\title{
Recent developments in lasers and the treatment of birthmarks
}

\section{Waner}

\section{Despite rapid advances during the past two decades there are still unanswered questions}

T here have been numerous advances during the past two decades in the treatment of birthmarks, concerning both efficacy and safety. Although initial results of laser treatment for portwine stains are encouraging, there remain unanswered questions about the long term benefits. The response of other birthmarks to laser therapy is variable, and much work still remains to be done.

\section{PORTWINE STAINS}

Laser treatment has become the standard of care for the management of portwine stains. The past two decades have witnessed the progression of these devices from crude, non-selective forms of treatment to highly sophisticated lasers capable of selective photothermolysis. In spite of this, the results of treatment leave much to be desired. Although the vast majority of portwine stains lighten significantly with treatment, only $15-20 \%$ clear completely. ${ }^{1}$ Moreover, a recent disturbing report revealed what many of us had suspected for some time: portwine stains can recur after treatment. ${ }^{1}$ The implications of this are yet to be determined. These findings lead to several important questions: why are we not able to clear more lesions and have there been any recent developments to improve our results?

\section{Vessel depth}

Two of the most important considerations are the depth of the vessels and their diameter. For some time, we have known that there is a significant variation in the depth of the vessels in portwine stains. Given the limited depth of penetration of yellow light ( $1-2 \mathrm{~mm}$ at $585 \mathrm{~nm}$ ), our inability to effectively treat the full thickness of some of the lesions seemed inevitable. Recent work has shown that there is indeed a correlation between the depth of the vessels and the response to laser treatment. ${ }^{2}$ In lesions where the mean depth of the vessels is greater than $1030 \mu \mathrm{m}$, the response was poor, whereas lesions with much more superficial vessels (mean vessel depth of less than $830 \mu \mathrm{m}$ ) responded well. In a separate study, the response to treatment also depended on the vessel depth. ${ }^{3}$

There are two ways to increase the depth of penetration of light. The first and most obvious is to increase the wavelength of light from the standard $585 \mathrm{~nm}$ to $595 \mathrm{~nm}$ or even $600 \mathrm{~nm}$. The second is to increase the spot size from $5 \mathrm{~mm}$ to $7.5 \mathrm{~mm}$ and even $10 \mathrm{~mm}$. Based on Monte Carlo modelling, the larger the spot size (up to $1 \mathrm{~cm}$ ), the greater the degree of scatter and the deeper the effective treatment depth. ${ }^{4}$

\section{Vessel diameter}

The diameter of the vessels also seems to play a critical role in whether or not the lesion will respond to treatment. Dierickx et al showed that pulsewidths in the millisecond domain would be more appropriate than the standard $500 \mu \mathrm{s}$ pulse width available on most pulsed dye lasers. ${ }^{5}$ This was based on the calculated thermal relaxation times of the vessels that make up these lesions. Therefore, in order to improve our ability to treat larger vessels, the pulse width needed to be increased from $500 \mu$ s to the millisecond range.

\section{Surface cooling}

The next advance came in the form of surface cooling. Nelson et al showed that cooling the skin surface with a cryogen spray just prior to the delivery of the laser pulse will accomplish two major advantages. ${ }^{6}$ Firstly, the likelihood of epidermal damage is reduced; and secondly, the pain of treatment is diminished. A third advantage in the form of greater efficacy soon became evident. Epidermal cooling enabled us to increase the fluence without the risk of epidermal damage. ${ }^{7}$ An increase in fluence translates into a more effective treatment and most importantly, a greater effect on the deeper vessels. This important advance led to surface cooling becoming a standard feature of pulsed dye lasers.
Several other methods of cooling soon became available. These included contact methods in which a cooled surface is placed against the skin during treatment, and non-contact methods in which a cold stream of air is directed at the surface during treatment. ${ }^{67}$ At this point, there are no clinical data comparing these methods. Anecdotal reports suggest that all are effective and there does not appear to be any major difference in efficacy.

\section{Lasers and light sources}

Pulsed dye lasers are the most widely used. Since their introduction in the late 1980s, numerous modifications have been made; the most recent features incorporated into these lasers include the following:

- Longer wavelengths (585-600 nm). Most physicians treat in the 585-595 $\mathrm{nm}$ range. Anecdotal comments suggest that $600 \mathrm{~nm}$ appears to be too long and less effective. ${ }^{8}$

- Bigger spot sizes. Most lasers will offer $7 \mathrm{~mm}$ and $10 \mathrm{~mm}$ options.

- Longer pulsewidths. At this time, there are no clinical data to support longer pulsewidths but anecdotal reports favour a $1500 \mu$ s exposure times. $^{8} \quad$ Clinical experience with pulsewidths longer than this has not resulted in improved results.

- Surface cooling. Several techniques of cooling are in use. These include cryogen spray, cold air, a cold window, and a cooled sapphire tip. There appear to be advantages and disadvantages of all of these methods but they do not appear to translate into any difference in efficacy. It is, however, most important that we use one of the methods of cooling.

The features mentioned above do appear to improve our results although at this point, good clinical data has not been published. These developments are however, recent, and it is expected that published clinical data will likely follow.

The most recent generation of pulsed dye lasers with all of the above features as well as a pulsewidth in the millisecond domain (up to $50 \mathrm{~ms}$ ) has become available. There are clear theoretical advantages to the longer millisecond pulsewidth, but whether or not these will translate into better clinical efficacy remains to be seen.

Other devices are also useful. These include KTP lasers and Nd:YAG lasers; more recently a source of non-coherent intense pulsed light has been used with some success.

KTP lasers emit a wavelength of 532 $\mathrm{nm}$ (green light) which is as well absorbed by oxyhaemoglobin as light at $585 \mathrm{~nm}$, but unfortunately there is 
greater absorption by melanin and more dermal scattering. ' This will limit the depth of penetration. On the other hand, these devices are capable of millisecond exposure times and can be delivered with surface cooling. It was therefore hoped that they would be useful to treat grade IV (c.f.) lesions. They have in fact been used successfully to treat all grades of portwine stain, but their use is not as widespread as pulsed dye lasers and to date, no published data attests to their efficacy. Nd:YAG lasers have very limited use and are unsafe in inexperienced hands. They can be used to treat cobblestones only. ${ }^{10}$

Sources of intense pulsed light with appropriate filtering and surface cooling are also useful for treating all grades of portwine stain but once again, their use is not as widespread as pulsed dye lasers. ${ }^{11}$ In skilled hands, these devices are beneficial.

\section{PATHOGENESIS AND CLASSIFICATION}

Evidence suggests that portwine stains are the result of a segmental, absolute, or relative deficiency in autonomic innervation of the post-capillary venules in the papillary dermis. ${ }^{12-14}$ This results in a progressive dilatation of the venules of the lesion throughout the life of the patient. An absolute deficiency in autonomic innervation will result in a more rapid progression with early hypertrophy and cobblestone formation. A relative deficiency results in a slower progress of the lesion. Since vessel diameter is such an important factor, a classification based on vessel size would seem logical. Such a classification exists and has both a clinical and a pathological basis. It is helpful in selecting a treatment modality. ${ }^{14}$

- Grade I lesions: vessel diameters are in the $80 \mu \mathrm{m}$ range. These lesions are light pink macules.

- Grade II lesions: vessel diameters measure up to $120 \mu \mathrm{m}$. These lesions are darker pink macules.

- Grade III lesions: vessel diameters measure up to $150 \mu \mathrm{m}$. These lesions are red macules.

- Grade IV lesions: vessel diameters are greater than $150 \mu \mathrm{m}$. These lesions are purple and may become papular.

Since laser treatment destroys ectatic vessels which are the consequence of a deficient autonomic innervation, laser treatment will only impact the effect and not the cause of a portwine stain. It therefore stands to reason that many, if not all, will recur since the autonomic deficiency seems to be segmental and is likely to affect all of the vessels, both large and small, in the affected area.

\section{A clinical approach}

Pulsed dye lasers are the most widely used lasers in this field. Their efficacy with grade IV lesions and lesions with cobblestone formation is poor, probably because of the fact that the vessels that make up these lesions have diameters that require millisecond exposure times. Although the addition of surface cooling and higher fluences may well change this, at this point, KTP lasers and intense pulsed light sources are useful for grade IV lesions. ${ }^{.1}$ In the presence of cobblestone formation, Nd:YAG lasers are useful, but if the cobblestones have been present for several years, surgical excision may be necessary. ${ }^{10}$ Surgical correction of soft tissue hypertrophy is occasionally helpful, especially with lip and eyelid hypertrophy. ${ }^{10}$ Surgical excision and full thickness skin grafting is, however, no longer warranted and given the success of laser treatment, this should be strongly discouraged.

\section{HEMANGIOMAS}

Pulsed dye lasers are essential to treat the superficial component of a hemangioma during both the proliferative phase of development and the phase of involution. During the proliferative phase, it is felt that repetitive treatments administered at 3-4 weekly intervals may diminish the ultimate size of the lesion, and in some cases, even completely resolve the lesion. ${ }^{15}$ Pulsed dye laser treatment has also been advocated for ulcerated lesions. ${ }^{16}$ While in most cases this is appropriate, in a very small number of patients, ulceration may in fact worsen after treatment, especially in segmental lesions. Skin resurfacing with both $\mathrm{CO}_{2}$ lasers and Er:YAG lasers is useful for treating the atrophic scarring that so often remains after an ulcerated segmental lesion has involuted. ${ }^{17}$ Further to this, the newer "combined" lasers that combine the use of more precise ablation with an Er:YAG laser and the effect of collagen shrinkage from a $\mathrm{CO}_{2}$ laser or a long pulsed Er:YAG laser would be, at least theoretically, better.

\section{PIGMENTED LESIONS}

The newer generation of Q-switched lasers can selectively destroy melanosomes and are thus useful for treating benign lesions, such as café au lait macules, lentigenes, and nevus of Ota.

\section{Café au lait macules}

Unfortunately, early reports of success have been tempered by the fact that many eventually recur after treatment. ${ }^{18}$ In a recent study, lesions with an irregular jagged edge had the most favourable response to treatment. ${ }^{19}$

\section{Nevus of Ota}

Several reports have confirmed the successful removal of these lesions with both Q-switched ruby lasers and Q-switched alexandrite ${ }^{20} 21$ lasers. Recurrence has not been reported.

\section{Congenital nevi}

The results of treatment with Q-switched ruby lasers have been disappointing. ${ }^{22}$ All appear to eventually recur.

Arch Dis Child 2003;88:372-374

\section{Author's affiliation}

M Waner, Arkansas Children's Hospital, Little Rock, Arkansas, USA

Correspondence to: Prof. M Waner, Arkansas Children's Hospital, 800 Marshall Street, Mail slot 668, Little Rock, Arkansas 72202, USA; wanermilton@uams.edu

\section{REFERENCES}

1 Orten SS, Waner M, Flock ST, et al. Portwine stains: an assessment of five years of treatment. Arch Otol Head Neck Surg 1996;122:1174-9.

2 Onizuka K, Tsuneda K, Shibata $Y$, et al. Efficacy of flashlamp-pumped pulsed dye laser therapy for port-wine stains: clinical assessment and histopathological. Characteristics. Br J Plast Surg 1995;48:271-9.

3 Motley RJ, Lanigan SW, Katugampola GA. Videomicroscopy predicts outcome in treatment of port-wine stains. Arch Dermatol 1997; 133:921-2.

4 Flock ST, Wilson BC, Patterson MS, et al. Monte Carlo modeling of light propagation in highly scattering tissues. I: Model predictions and comparison with diffusion theory. IEEE Trans Biomed Eng 1989;36:1 162-8.

5 Dierickx CC, Casparian JM, Venugopalan V et al. Thermal relaxation of port-wine stain vessels probed in vivo: the need for $1-10$ millisecond laser pulse treatment. J Invest Dermatol 1995;105:709-14.

6 Nelson JS, Milner TE, Anvari B, et al. Dynamic epidermal cooling during pulsed laser treatment of port-wine stain. Arch Dermatol 1995;131:695-700.

7 Raulin C, Greve B, Hammes S. Cold air in laser therapy: first experiences with a new cooling system. Lasers Surg Med 2000;27:404-10.

8 Anon. Unpublished notes from a panel discussion on the treatment of portwine stains at "Controversies in Cutaneous Laser Surgery", Woodstock, Vermont, 2000

9 Van Gemert MJC, Welch AJ, Pickering JW, et al. Wavelengths for laser treatment of port wine stains and telangiectasia. Lasers Surg Med 1995:16:147-55.

10 Waner M, Suen JY. Treatment options for the management of vascular malformations. In: Waner M, Suen JY, eds. Hemangiomas and vascular malformations of the head and neck. New York: John Wiley \& Sons, 1999:315-50.

11 Angenmeier M. Treatment of facial vascular lesions with IPL. Journal of Cutaneous Laser Therapy 1999;1:95-100.

12 Smoller BR, Rosen S. Port-wine stains: a disease of altered neural modulation of blood vessels. Arch Dermatol 1986;122:177

13 Rydy M, Malm M, Jernbeck J, et al. Ectatic blood vessels in port-wine stains lack innervation: possible role in pathogenesis. Plast Reconstr Surg 1991;87:419.

14 Waner M, Suen JY. The natural history of vascular malformations. In: Waner $M$, Suen JY, eds. Hemangiomas and vascular malformations of the head and neck. New York: John Wiley \& Sons, 1999:47-82. 
15 Garden JM, Bakus AD, Paller AS. Treatment of cutaneous hemangiomas by the flashplump-pumped pulsed dye laser: prospective analysis. J Pediatr 1992; 120:555-60.

16 Morelli JG, Tan OT, Yohn JJ. Treatment of ulcerated hemangiomas in infancy. Arch Pediatr Adolesc Med 1994;148: 1 104-5.

17 Waner M, Suen JY. Treatment options for the management of hemangiomas. In: Waner $M$,
Suen JY, eds. Hemangiomas and vascular malformations of the head and neck. New York: John Wiley \& Sons, 1999:233-62.

18 Goldberg DJ. Laser treatment of pigmented lesions. In: Alster TS, Apfelberg DB, eds. Cosmetic laser surgery: a practitioner's guide. New York: Wiley-Liss, 1999:279-88.

19 Levy JL, Mordon S, Pizzi-Anseluc M.

Treatment of individual café au lait macules with the Q-switched Nd:YAG: a clinicopathologic correlation. Journal of Cutaneous laser Therapy 1999:1:217-23.

20 Watanabe S, Takahashi H. Treatment of nevus of Ota with the Q-switched ruby laser N Engl J Med 1994;331:1745-50.

21 Alster TS, Williams CM. Treatment of nevus of Ota by the Q-switched alexandrite laser. Dermatol Surg 1995;21:592-6.

22 Geronemus RG. Q-switched ruby laser therapy of nevus of Ota. Arch Dermatol 1992;1 28: 1618-22.

\section{POSTCARD FROM THE ROAD}

\section{A leap into the unknown-working overseas}

ike most of these things, the opportunity to work for a year

in Brisbane came about by chance, one in a series, in a lifetime filled with lucky circumstances.

I had already decided, with my wife, to take six months of unpaid leave in order to see a bit of the world. More about this another time. The chance to work in Brisbane came up and we rapidly combined it with our travel plans. It is usually hard for doctors working in a March/September system to fit in with doctors working in a January/January system without upsetting someone. Our plans for time out to travel gave us much needed flexibility to reconcile this.

Part of me would have liked to work in the developing world, but for complicated personal reasons this was not possible. So, the question arises: What is the point of working in another developed country? Will the experience be significantly different from staying at home? To try to address this valid point, I set myself some goals and some questions that I wanted to try to answer by the end of my time in Australia. I've had varying success.

Firstly I wanted to get a feel for which of the problems with NHS are the consequence of it being the NHS, and which are common to any health monolith. Clearly I only have an $\mathrm{n}$ of 2 , but I do have a better feel for what we do because that is what we've always done, and I've seen some of the problems we share with Australia solved in different ways.

Secondly I was keen to experience some branches of paediatrics my region or country couldn't offer meor could only offer me with greater commitment than I could give in a five year training programme. Thus, I've had short periods of experience in paediatric intensive care, with fixed wing and helicopter retrieval, in oncology, and in rural and (extremely) remote paediatrics. I've also been the Chief Resident, a role which isn't currently found in any hospital in the UK.

And thirdly I wanted to find out more about some of the specific issues I've written about here-the 40 hour week, obesity, teenage smoking, aboriginal health, and so on.

What are the down sides of working overseas?

Well, there are conflicting messages about the amount of time that will be counted towards your CCST when you spend time out of rotation. At various times I was told anything between one and two years of my total two years working overseas. The postgraduate deans are currently under pressure to move SpRs through the system, and so now there is a trend to include more out of programme time. I'd have to be honest and say that the issue didn't really worry me greatly; so I might be a consultant for a year less in the grand scheme of things-where's the hurry? Oddly enough the Royal Australasian College of Physicians allows up to six of the total seven training years spent outside Australia. This causes a little anxiety among some senior members, who argue that this isn't really an Australian training at all. There must be some

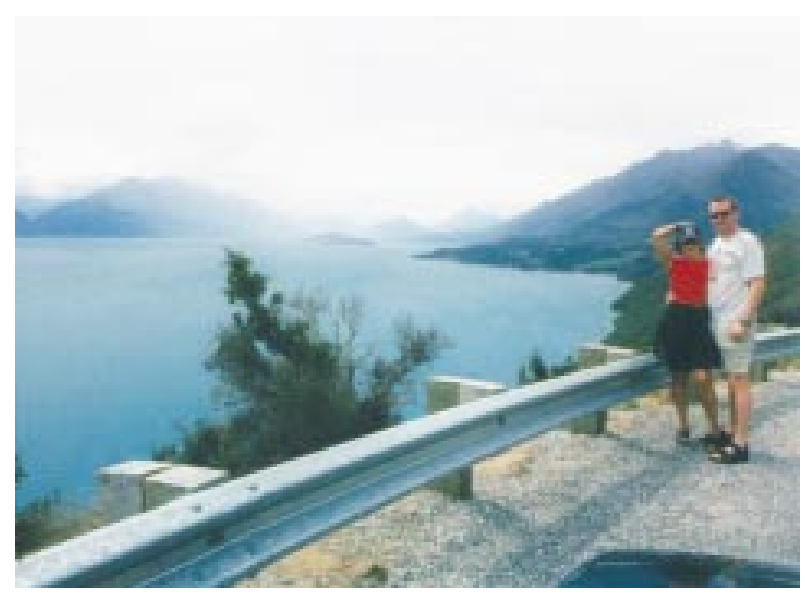

happy—although entirely arbitrary-middle ground. Unless the supervising body had confused training with service, of course ...

It's been expensive too. Oh, I've earned loads, but being on the other side of the world from your usual home gives you a different perspective. It would rude to go all that way and not see the place properly, wouldn't it? It does, however, leave my pension in a terrible mess.

Lastly the stresses involved in dealing with a whole different set of regulating bodies-from immigration, through registration, to colleges, and the health monoliths themselves-can be huge. We got married a few months before leaving for Australia, and I can honestly say-with no disrespect to the institution-that the wedding was a breeze compared with the rest of it.

At the end of it all, in answering the question "Was it worth it?" I would have to say yes, emphatically and without hesitation.

A few tips for anyone considering anything similar. Firstly don't underestimate the disruption and cost. Do the old backpackers' technique for estimation of expenses: work out how much you'll need, and then double it. If you are used to backpacking, then double it again. Secondly, establish and use clear lines of communication. Get an account with a telecom company offering cheap phone calls to wherever you are going. Follow up post; send items by international registered mail if they are at all important, and make a polite phone call after two weeks if you've heard nothing. Email can make this easier, but people have varying levels of ability with this tool, and you need to remain contactable.

Lastly, if you think you would like to do it, then you should. I doubt very much you will regret it.

I D Wacogne

lan Wacogne is a consultant in general paediatrics, Birmingham Children's Hospital, UK; ian.wacogne@btinternet.com 